\title{
TWENTY-FIVE VOLUMES OF FUNDAMENTA MATHEMATICAE
}

The publication at the end of 1935 of the twenty-fifth volume of the Fundamenta Mathematicae represents a notable event in the mathematical life of the whole world. Fundamenta Mathematicae was founded in 1920 by Z. Janiszewski, S. Mazurkiewicz, and W. Sierpinski. The idea of founding this periodical was due chiefly to the extremely gifted young mathematician, Zygmunt Janiszewski (b. 1888, d. 1920) who was interested and active in various fields connected with foundations of mathematics. His premature death deprived him from enjoying the realization of his dreams-to have an international periodical devoted mainly to foundations of mathematics. The first volume of Fundamenta Mathematicae appeared in 1920, shortly after his death. Under masterful guidance of his colleagues, S. Mazurkiewicz and W. Sierpinski, Fundamenta Mathematicae immediately developed into a unique periodical which attracted international recognition and cooperation, and whose history became the history of development of the modern theory of functions and point sets.

The richness of material furnished by Polish mathematicians and by their foreign colleagues, led to the founding (in 1929) of a new periodical, Studia Mathematica, ${ }^{*}$ devoted mainly to problems of functional analysis. This did not decrease in the least the interest and importance of the Fundamenta Mathematicae, which reached its silver jubilee volume in a state of youthful maturity and with hopes for coming vigorous development.

In the twenty-five volumes of the Fundamenta published during the period 1920-1935, there participated 170 authors who contributed 732 papers. The present jubilee volume is twice as large as the other volumes $(582+15 \mathrm{pp}$.$) , has$ a magnificent appearance, and contains 48 papers written by 45 authors, nine of them residing in this country.

This splendid success is due not only to the interest and esteem in which the mathematical world holds the Fundamenta, not only to the authoritative guidance of its editors and secretary, K. Kuratowski, but also to the generous support given by the government. Let us hope that this support will continue in the future, and that the Fundamenta in years to come will maintain its honorable place among the mathematical periodicals of the world.

\section{J. D. TAMARKin}

* Quite recently, in 1935, there was founded in Poland a new important periodical, Acta Arithmetica, devoted to number theory! Thus Poland is a unique country supporting three highly specialized periodicals devoted to pure mathematics. 